\title{
Birth Order as a Possible Correlate of Child Abuse
}

\author{
Alokan Funmilola Bosede \\ Department of Guidance and Counselling, Faculty of Education \\ University of Ado-Ekiti, Nigeria
}

\begin{abstract}
The study investigated the difference in the level of abuse experienced based on the birth order of a child among public secondary school students in south-west Nigeria. A descriptive research design of exploratory type was adopted for the study. A total of 1 , 440 public secondary school students in 36 schools from 9 local government areas in 3 southwestern states of Nigeria, were sampled for this study. Out of these students, 695 students were found to be abused and their responses formed the data that were analysed for this study. A self constructed questionnaire titled Child Abuse Questionnaire (CAQ) was administered on the students after validation. The instrument has construct validity coefficient of 0.83. The statistical technique used was a one-way ANOVA. The result of the analysis showed that there is a significant difference between the level of abuse experienced by the first child and the children who occupy other birth positions. Based on the finding, it is recommended among others that parents should not give their first child tasks that are too heavy for them and that every child needs tender care of the parents including the first born child.
\end{abstract}

\section{Introduction}

Child abuse is the physical or psychological/emotional maltreatment of children. In the United States, the Centers for Disease Control and Prevention [3] defined child maltreatment as any act or series of acts of commission or omission by a parent or other caregiver that results in harm, potential for harm, or threat of harm to a child. Most child abuse occurs in a child's home, with a smaller amount occurring in the organizations, schools or communities the child interacts with. There are four major categories of child abuse: neglect, physical abuse, psychological/emotional abuse and sexual abuse.

Different jurisdictions have developed their own definitions of what constitutes child abuse for the purposes of removing a child from his/her family and prosecuting a criminal charge. The mental health practitioners states that child abuse is defined as any recent act or failure to act on the part of a parent or caretaker which results in death, serious physical or emotional harm, sexual abuse or exploitation, an act or failure to act which presents an imminent risk of serious harm.

Neglect is the instance in which the responsible adult fails to adequately provide for various needs, including physical (failure to provide adequate food, clothing or hygiene), emotional (failure to provide nurturing or affection) or educational (failure to enroll a child in school). Physical abuse is physical aggression directed at a child by an adult. It can involve striking, burning, choking or shaking a child. The transmission of toxins to a child through its mother (such as with fetal alcohol syndrome) can also be considered physical abuse in some jurisdictions. Bakan [2] said types of injuries inflicted upon children are many and varied; children have been whipped, beaten, starved, drowned, smashed against walls and floors; children have also been tied and kept in upright position for long period, placed on roadways where automobiles could run them; they have between knifed and shot. The distinction between child discipline and abuse is often poorly defined. Cultural norms about what constitutes abuse vary widely. Among professionals as well as the wider public, people do not agree on what behaviours constitute abuse [12]. Haeuser [6] reported that cultural norms that sanction physical punishment are one of the causes of child abuse, and have undertaken campaigns to redefine such norms.

Psychological/emotional is hard to identify. This form of abuse includes name-calling, ridicule, degradation, destruction of personal belongings, torture or destruction of a pet, inappropriate or excessive demands, withholding communication and routine labelling or humiliation. While sexual abuse is involvement of dependent, developmentally immature children and adolescents in sexual activities which they do not fully comprehend and to which they are unable to give informed consent. This includes touching, fondling and penetration [11].

Children with a history of neglect or physical abuse are at risk of developing psychiatric problems, or a disorganized attachment style [9]. Victims of childhood abuse, it is claimed, also suffer from different types of physical health problems later in life. Some reportedly suffer from some type of chronic head, abdominal, pelvic or muscular pain 
with no identifiable reasons. The effects of child abuse vary, depending on its type. Takele [16] found that childhood emotional and sexual abuse were strongly related to depressive symptoms, while exposure to verbal abuse had a moderately strong association, and physical abuse a moderate one. For depression, experiencing more than two kinds of abuse exerted synergetically stronger symptoms. Childhood verbal abuse had a stronger association with anger-hostility than any other type of abuse studied, and was second only to emotional abuse in its relationship with dissociative symptoms.

New researches illustrate that there are strong associations between exposure to child abuse in all its forms and higher rates of many chronic conditions. The strongest evidence comes from the Adverse Childhood Experiences (ACE's) series of studies which show correlations between exposure to abuse or neglect and higher rates of chronic conditions in adulthood, high risk health behaviours and shortened lifespan [8].

All these negative features of child abuse negate the United Nations Convention and O.A.U Charter on Rights of the Child [17]. Nigeria is a signatory to the Charter. Among the basic principles of children's rights are:

(1) Every child has the right to live and be allowed to develop.

(2) Every child has the right to express opinions and freely communicate them on any issues, subject to restriction under law.

(3) Every child is entitled to adequate rest, recreation (leisure and play) according to his or her age and culture.

(4) Every child is entitled to protection from any act that interferes with his or her privacy, honour and reputation.

(5) Every child (male and female) is entitled to receive compulsory basic education and equal opportunity for higher education, depending on individual ability.

(6) Every child is entitled to good health, protection from illness, proper medical attention for survival, personal growth and development.

(7) Every child must be protected from indecent and inhuman treatment through sexual exploration, drug abuse, child labour, torture, maltreatment and neglect.

In a family, where a child places in the birth order can have an effect on the personality of a child, on how he sees himself and on how the parents see and relate to him. Alfred Aldler, an Austrian psychiatrist, and a contemporary of Sigmund Freud and Carl Jung, was one of the first theorists to suggest that birth order influences personality. He argued that birth order can leave an indelible impression on an individual's style of life. Some birth order factors that should be considered are the spacing in years between siblings, the total number of children, and the changing circumstances of the parents over time.

Some literature reviews tend to find minimal effects for birth order. Ernst and Angst [5] reviewed some research published between 1946 and 1980. They also did their own study on a representative sample of 6,315 young men from Switzerland. They found no great effects of birth order. Harris [7] in her study, suggests that birth order effects may exist within the context of the family of origin, but that they are not enduring aspects of personality. When people are with their parents and siblings, firstborns behave differently than laterborns, even during adulthood.

Stein [15] made a broad simplification of Adler's theory of birth order characteristics, highlighting the child's position, family situation and child's characteristics. The child who is the only child in the family retains $200 \%$ attention from both parents, may become rival of one parent and can be overprotected and spoilt. The child likes being the center of adult attention and often has difficulty sharing with peers. The oldest child in the family has to learn to share, parents expectations are usually very high, he is often given responsibility and expected to set an example. The child may become authoritarian or strict, feels power in his right and can become helpful if encouraged, may turn to father after birth of next child. The second child has a pacemaker, there is always someone ahead. The child is more competitive, wants to overtake older child, may become a rebel or try to out do everyone, and competition can deteriorate into rivalry.

The middle child is 'sandwiched' in, may feel squeezed out of a position of privilege and significance. The child may be even-tempered with 'take it or leave it' attitude; may have trouble finding a place or become a fighter of injustice. The youngest child has many mothers and fathers, older children try to educate him, he is never dethroned. He may have huge plans. The youngest child is frequently spoilt.

In case of the twins, one is usually stronger or more active, and parents may see one as the older. They can have identity problems and the stronger one may become the leader. The 'ghost child' is the child born after the death of the first child, may have a 'ghost' in front of him, mother may become overprotective. The child may exploit mother's overconcern for his well-being, or he may rebel and protest the feeling of being compared to an idealized memory. Parents of the adopted child may be so thankful to have a child that they spoil him. They 
may try to compensate for the loss of his biological parents. The child may become very spoilt and demanding; eventually, he may resent or idealize the biological parents.

The only boy among girls is usually with women all the time, if father is away. The child may try to prove he is man in the family, or become effeminate. The only girl among boys is surrounded by brothers that may act as her protectors. She can become very feminine or become a tomboy and outdo the brothers; she may also try to please the father. In a family of all boys, the boy can be dressed as a girl if mother wanted a girl. The child may capitalize on assigned role or protest it vigorously. In a family of all girls, the girl may be dressed as a boy and she may capitalize on assigned role or protest it vigorously.

From Adler's theory, one could see that there is tendency for children in certain birth positions to be saddled with much responsibility than they could bear and there is also the tendency for some to be neglected. These are features of abuse. There are also certain characteristics that can predispose a child to abuse.

In most cases, children who are abused or neglected suffer greater emotional than physical damage. A child who is severely maltreated may become depressed or develop suicidal, withdrawn or violent behaviour. As he gets older, he may use drugs or alcohol, try to run away, refuse discipline or abuse others. As an adult, he may develop marital and sexual difficulties, depression or suicidal behaviour. Some abused children often repeat the vicious cycle by becoming abusive parents. This study is based on finding out the relationship between the birth order of a child and child abuse with a view of determining how to manage the situation and reduce cases of child abuse in the society.

\section{Statement of the Problem}

Child abuse appears to be prevalent in our society. It is a common sight to see children engaged in petty-trading and street begging, while some hawk for their parents and guardians when they should be laying a solid foundation for their future. There are cases of parents brutalizing their children in the name of correction. One also sees cases of child prostitution in order to get money.

The average school teacher today has on his hands a crisis resulting from parents' abdication of their responsibilities. This, many teachers believe, has adversely affected the character and outputs of students [1]. In schools, one observed students who are affected by anxiety, depression, and passive or withdrawal behaviour. Some of the students engage in aggressive, destructive and inappropriate acts or delinquent behaviour. One sees neglected children stealing or begging for food, students to coming to schools regularly and students sleeping during lessons almost all the time. Some of these children complain about having no time to study at home because of the responsibilities they shoulder at home. Some of them also seek inappropriate affection from others. All these types of negative behaviours are wide spread in the country and they usually affect students' academic performance.

Egeland and Erickson [4] reported that maltreatment affects intellectual functioning and it makes children to lose interest in exploring their environment. It was also observed and documented that affectionate care is extremely important for healthy human development, and that lack of such care can result in severe deficit and can even be fatal. Abused children grow up in a world of uncertainty, inconsistency, lies, violation, pain and abandonment. Victims of child abuse have learnt to live and adapt to the abusive environment, so their behaviours can appear superficially moody, dysfunctional, unpredictable, offensive, antagonistic or hostile. To this end, the following research hypothesis was raised.

\section{Hypothesis}

There is no significant difference in the level of abuse based on the birth order of the child.

\section{Methodology}

The researchers used descriptive research design of exploratory type. The plan of study involved the use of questionnaire to collect data in order to test the hypothesis raised in the study. The target population for this study was made up of public secondary school students in South West Nigeria, who were within the age range of 9-18 years. Multistage random sampling was used in drawing out the sample.

Since the study is on South West Nigeria as a whole, the researchers recognized the states, local governments and schools. The researchers therefore selected the sample in stages.

Out of the six states in the South West Nigeria, three were chosen. Also, out of the local government areas in each of the three states, three were selected by simple random sampling technique. In each local government, four secondary schools were selected. Copies of questionnaire were given out to 1440 students in 36 schools. Exploratory method was then used. Out of these questionnaires, the researchers 
brought out those of abused students; that is, those who scored 200 and above out of the 300 score obtainable. The respondents that scored 200 and above were 695 in number. Their questionnaire were used in data analysis.

A self-designed questionnaire called Child Abuse Questionnaire (CAQ) was used for this study. Part A was designed to collect information on background characteristics of respondents; including birth order of the child in the family, part B consisted 28 items which elicited students' responses on child labour, sexual abuse, physical abuse and child neglect.

The methods used in validating the instrument were face, content and construct validities. For face validation, the experts determined at face value the appropriateness of the instrument in measuring what was being studied, to ascertain if the instruments elicit the intended responses on child abuse and the psychological factors.

Expert judgments were used in determining the content validity. The experts checked the extent to which the items were representative of content, practices and factors specified by the theoretical concept being measured. The scores of the test administration on 30 abused secondary students were correlated with that of Child abuse and Neglect Test (2007) using Pearson Product Moment Correlation, a correlation coefficient of 0.756 was obtained. This indicated that the research instrument used (CAQ) clearly measures the same construct with CANT (2007).

A reliability test was also carried out on 20 abused secondary school students using Pearson Product Moment Correlation. A reliability coefficient of 0.83 was obtained. On the basis of these psychometric properties, the instrument was found to be suitable for data collection.

Copies of the questionnaire were distributed by the researchers and the school counsellors to a sample of 1, 440 students in 36 schools. Researchers' presence during administration enhanced better understanding of the items in the instrument. Copies of the questionnaire were collected back immediately after completion by the researchers.

The data generated were analysed using oneway ANOVA. The hypothesis was tested at 0.05 level of significance.

\section{Test of Hypothesis}

Ho: There is no significant difference in the level of abuse based on the birth order of the child.

In testing this hypothesis, the data obtained on birth order of respondents were analysed by using one way ANOVA
Table 1. One way ANOVA Summary of Birth Order and Level of Child Abuse

\begin{tabular}{|l|l|l|l|l|l|}
\hline Source & SS & Df & Mss & Fcal & Ftable \\
\hline Between & 1013. & 2 & 506. & & \\
Groups & 441 & & 720 & \multirow{2}{*}{3.306} & 3.078 \\
Within & 106073. & 692 & $\begin{array}{l}153 . \\
285\end{array}$ & & \\
Groups & 500 & & & \\
Total & $\begin{array}{l}107086 . \\
900\end{array}$ & 694 & & & \\
& & & & \\
\hline
\end{tabular}

The result showed that the observed F-ration value for birth order is 3.306 while the table value is 3.078. The result revealed that there is a significant relationship between birth order of a child and child abuse. Thus, the null hypothesis that says there is no significant difference in the level of abuse based on the birth order of the child was rejected. Hence, Scheffe Post-Hoc analysis was done to find the difference pair-wise (see table 2).

Table 2. Scheffe post-Hoc of Birth Order and Level of Child Abuse

\begin{tabular}{|l|l|l|l|l|l|}
\hline Birth order & 1 & 2 & 3 & & \\
\hline $1^{\text {st }}$ child & & $*$ & & & \\
\hline $2^{\text {nd }}$ child & & & $*$ & & \\
\hline Other positions & & & & & \\
\hline
\end{tabular}

*The mean difference is significant at 0.05 level.

Table 2 shows that the level of child abuse experienced by first child is significantly different from the level of abuse experienced by the second child similarly, the level of abuse experienced by the second child is significantly different from the level of abuse experienced by children who occupy other birth positions.

The probable explanation could be that the parents expectation on the first child is usually high. In most cases, a lot of responsibilities that are burdensome are piled on the first child. The first child is expected to take care and also lay good example for the younger ones. If he/she does not meet this expectation, he/she would be severely punished for it. It is common knowledge that the first born child experiences the iron-hand discipline of parents most. In some homes, house chores are left for the first child alone to do. Atimes, the first child is exposed to child labour to support the family income which could affect his academic performance. In some cases, the first child is forced into a career that he is not interested in, just to boost the Birth order 123 1st child *2nd child *Other positions prestige of the family. Mandell [10] supported this by saying that first borns are guinea 
pigs and generally their parents have no idea what they are doing. She said no wonder most of the astronauts are first borns; they will do anything to get away from those parents who hounded them mercilessly. Rothbart [14] opined that some parents may set an unnaturally high standard for performance for their first-born. In the same vein, Richardson and Richardson [13] found that oldest children are given more responsibilities than the younger ones and they feel more pressure to succeed. Too much responsibility piled upon the oldest child in the home is an abuse.

On the other hand, children who occupy other birth positions do not carry the burden of too high expectation from parents. They are not especially hounded to be models for anybody; and in terms of discipline, the parents are becoming a little bit tired.

\section{Conclusion}

Evidence from this study has led the researcher to conclude that there is a relationship between the birth order of a child and child abuse. Also, the first child in the family is usually predisposed to child abuse.

\section{Recommendations}

Based on the findings of the study, the following recommendations were made

1. Parents should deal with their children with understanding. They should not give their first child tasks that are too heavy for them.

2. Every child should be allowed to have a period of leisure and recreation, including the first born child.

3. Every child needs tender care of the parents, including the first born child.

4. Parents should not force their children into a vocation of their own choice, but should guide the children according to their interest and ability.

5. School counsellors should be on the look-out for students who have problems such as coming late to school and poor academic performance (they could be first borns). If they are first borns or if they even occupy other birth positions, the counsellor should liase with the parents to make the home environment condusive for the students.

\section{References}

[1] Ale A. (2007). Where have the parents gone: Family experts decry neglect at the home front. Saturday Punch March 17, P3

[2] Bakan, D. (1971). Slaughter of the innocents San Francisco: Jossey-Brass.
[3] Centers for Disease Control and Prevention (2008).Child Maltreatment Surveillance: Uniform Definitions for Public Health and Recommended Data Elements,

http://www.cdc.gov/ncipc/dvp/cmp/cmpsurveillance. htm. Retrieved on 26/11/2009.

[4] Egeland, B. and Erickson, M.F. (1987). Psychological unavailable care giving. In M.R. Brassard, R. German and S.N. Hart(eds). Psychological Maltreatment of Children and Youth. New York: Pergamon press.

[5] Ernst, C. and Angst, J. (1983). Birth Order: Its Influence on Personality. Berlin: Springer.

[6] Haeuser, A.A. (1990). Banning parental use of physical punishment: Success in Sweden. International.

[7] Harris, J. R. (2006). No Two Alike: Human Nature and Human Individuality. W.W. Norton. en.wikipedia.org/../Judith_Rich_Harris

[8] INSEE (1987). Study of Living Conditions. A Survey study. IRDES, biblio No 1010, Pp 59-63. Paris.

[9] Malinosky-Rummel R., and Hansen D. J (1993). Long- term consequences of childhood physical abuse. Psychological Bulletin. 114 (1): 68-79.

[10] Mandell, S.L. (2007). Birth Order. Whole family Center Inc. wholefamily.com.

[11] National Association of Counsel for Children (2007). Children and the Law. Denver, Colorado. http/wwww/helpguide.org. Retrieved on 31/1/2007

[12] Noh Anh, H. (1994). Cultural diversity and the definition of child abuse. In Barth, R.P. Child Welfare Research Review. Columbia University Press.

[13] Richardson, R.W. and Richardson, L.A. (1990). Birth Order and You. North Vancouver, British Columbia: Self-Counsel Press.

[14] Rothbart, M.K. (1972). Birth Order and motherchild interaction in an achievement situation. In U.Brofenbrenner (Ed). Influences on Human Development. Hinsdale, Illinois: The Dryden Press Inc.

[15] Stein H.T. (2008). Alderian Overview of birth order characteristics. Distance Training in Classical 
Alderian Psychotherapy. Alfred Alder Institutes of San Francisco and Northwestern Washington.

[16] Takele, H. (2006). Impact of Childhood Abuse on Adult Health. Ambeton University.

[17] United Nation children's Fund (1989). United Nations Convention on the Right of the Child and Organization of African Unity Charter. Lagos Country Office. 